\title{
. \\ Religiosity and Spirituality of German-Speaking Pilgrims on the Way of St. James
}

\author{
Detlef Lienau *(1), Stefan Huber (1) and Michael Ackert (1)
}

check for

updates

Citation: Lienau, Detlef, Stefan

Huber, and Michael Ackert. 2022.

Religiosity and Spirituality of

German-Speaking Pilgrims on the

Way of St. James. Religions 13: 51.

https://doi.org/10.3390/rel13010051

Academic Editor: Mariano P. Barbato

Received: 1 December 2021

Accepted: 23 December 2021

Published: 6 January 2022

Publisher's Note: MDPI stays neutral with regard to jurisdictional claims in published maps and institutional affiliations.

Copyright: (c) 2022 by the authors. Licensee MDPI, Basel, Switzerland. This article is an open access article distributed under the terms and conditions of the Creative Commons Attribution (CC BY) license (https:// creativecommons.org/licenses/by/ $4.0 /)$.
Institute of Empirical Research on Religion, Universität Bern, 3012 Bern, Switzerland; stefan.huber@theol.unibe.ch (S.H.); michael.ackert@theol.unibe.ch (M.A.)

* Correspondence: detlef.lienau@theol.unibe.ch

Abstract: The article examines the intensity and structure of religiosity and spirituality of Germanspeaking foot and bicycle pilgrims on the Way of St. James within the framework of a multidimensional model of religiosity. The following nine aspects are distinguished: religious questions, faith, religious and spiritual identity, worship, prayer, meditation, monistic and dualistic religious experiences. Data of $N=425$ German-speaking pilgrims of the Way of St. James from the years 2017 and 2018 are analyzed. The data of the Religion Monitor 2017 from Germany, Austria, and Switzerland $(N=2837)$ serves as a population-representative comparison sample. Descriptive statistics, $t$-tests, and multiple regression analyses are used to analyze and to compare the two groups. The results show that German-speaking pilgrims in the analyzed sample have substantially higher values on all dimensions of religiosity than the general population in Germany, Austria, and Switzerland. This difference is most pronounced in the spiritual self-concept. However, for most pilgrims, the categories religious and spiritual are not mutually exclusive. Rather, spirituality forms a basis shared by almost all pilgrims in the sample, to which religiousness is added for many. Further, results are discussed in the light of the existing foot and bicycle pilgrimage research. Conclusively, it can be said that tourism and church actors should consider the religious character of pilgrims, which remains despite all changes in the religious landscape.

Keywords: pilgrims; German-speaking; Way of St. James; religiosity; spirituality; multidimensional structure of religiosity; centrality of religiosity scale; religious self-concept; spiritual self-concept

\section{Introduction}

Walking (and cycling) pilgrimage has experienced a renaissance in Europe in recent decades $^{1}$. Even though the numbers of pilgrims arriving at their destination in Santiago de Compostela on the Camino de Santiago, at ca. 347,000 registered pilgrims in 2019 (Oficina del Peregrino Homepage n.d., statistics of pilgrim's office), fall far short of traditional Catholic pilgrimage sites, non-motorized pilgrimage can be understood to be a vital expression of religious motifs and therefore also their dynamic. Prototypical of pilgrimage is the Camino Francés through Spain, which is considered the pilgrimage route in Europe and has by far the highest number of pilgrims. Therefore, a lot of the pilgrimage research in Europe today refers to it. For a good three decades, the numbers of pilgrims on foot have been steadily increasing on a constantly growing network of pilgrimage routes. Correspondingly, the media presence, which goes far beyond the actual practice, in film (e.g., "The Way," Estevez 2010) and book (e.g., the most widely printed German-language non-fictious book is HaPe Kerkeling's pilgrimage account "Ich bin dann mal weg." (Kerkeling 2006)) which indicates through popular literature that pilgrimage has noticeable appeal. In multiple cases, pilgrimage is taken as a metaphor or in its practice as an indicator that can show the current change in the shape of the religious (Hervieu-Léger 2004). 


\subsection{Research Object and Research Question}

One focus of interest in research on contemporary pilgrimage in Europe is the sociological classification of pilgrimage in the context of the current transformation of religion, religiosity, and spirituality (e.g., Lienau 2018). In this context, one of the main questions is the motivation of pilgrims (e.g., Gamper and Reuter 2012). In contrast, there are few studies on the general structure and relevance of pilgrims' religiosity and spirituality beyond the act of pilgrimage (e.g., Oviedo et al. 2014). Given this state of research, this paper brings pilgrims' religiosity and spirituality into focus. The attention is on the following questions, which are always in relation to German-speaking pilgrims on the Way of St. James:

1. How does the multidimensional model apply to pilgrims' religiosity and spirituality? More precisely:

a. How strongly do pilgrims believe in the existence of a spiritual realm?

b. How often do the pilgrims think about transcendence?

c. Do they seek contact with the transcendency, and how often do they have experiences with it?

d. Furthermore, how strong are pilgrims connected with churches?

2. How do the pilgrims understand themselves in relation to the following terms:

a. "religious" and

b. "spiritual"?

3. To what extent can the religious and spiritual self-concept of pilgrims be explained by the dimensions of the multidimensional model or religiosity?

4. How do pilgrims differ from the population in Germany, Austria, and Switzerland regarding the dimensions of the multidimensional model of religiosity and religious and spiritual self-concept? What aspects are typical of pilgrims?

Regarding these main questions, the paper discusses the phenomenon of pilgrimage in the context of contemporary transformations of the religious landscape in Western Europe. While doing so, this study bases on a substantive concept of religion, which, however, is not narrowed theistically, but is broadly conceived to include pantheistic concepts (Huber 2009). "In this perspective, the essential characteristic of religious experience and behavior consists in a meaningful reference to a reality perceived as higher, to which an essential relevance for one's own life is attributed. In the history of religion this higher reality is often named as God, divinity, higher power, spirit, or spiritual world. "(Huber et al. 2020, p. 7).

\subsection{Research Overview}

Pilgrimage is no longer a distinctly religious phenomenon, or even one that follows solely the trajectories of traditional Catholic forms (Collins-Kreiner 2016's article is influential in this regard). Rather, religious, spiritual, secular, touristic, sporting, social, biographical, and cultural aspects intersect in the phenomenon of pilgrimage. Accordingly, the study of pilgrimage involves a broad field of disciplines, such as geography, sociology, ethnology, theology, psychology, history, religion-, media-, and tourism-studies. For the field of quantitative-empirical studies, which is particularly relevant here, social science studies are especially important.

In the diversity of facets and corresponding perspectives on the phenomenon in the literature, the question of the relevance of the religious-spiritual dimension remains predominant. Most studies refrain from taking extreme positions; neither purely seculartouristic motivations nor purely religious-spiritual ones are asserted. Within the broad consensus that pilgrimage is also a religious phenomenon, there are gradations in the assessment of how essential religious aspects are, whether an increasing or decreasing trend can be observed, and how more traditional-religious and newer moments relate to each other.

Pilgrimage is changing continually, in terms of human beings on the way, their motivation, as well as the accomplishment of the pilgrimage itself. Pilgrimage has habitually 
been characterized by diverse interests (Herbers 2006; Oviedo et al. 2014), but a clear shift in emphasis is evident in the current upsurge of foot pilgrimage on the Camino de Santiago. Studies have come to different conclusions about the weight given to religious, spiritual, and other motivations. In some cases, the Way of Saint James is considered an example of a shift from a purely religious to a touristic-spiritual phenomenon (Kim et al. 2019; Lois-González and Santos 2015; Lopez et al. 2017). In this frame Amaro et al. (2018) identify a trend from older studies emphasizing religious motives (e.g., Fernandes et al. 2012; Millán Vázquez de la Torre et al. 2012) to more recent ones emphasizing spirituality, personal clarity, sport, and experience seeking (e.g., Nilsson and Tesfahuney 2016; Oviedo et al. 2014; Schnell and Pali 2013). Besides, Margry (2015) observes shifts between different forms of the religious. The data though are not fully consistent in every regard. Most recently, Heiser (2021) highlighted the relevance of the religious, noting a coexistence of traditional religious and contemporary spiritual aspects. Clear oppositions and dichotomies such as individual instead of communal/institutional, profane instead of sacred, fun instead of serious, and invisible instead of public do not do justice to the phenomenon, because besides undisputed trends such as experiential orientation and corporeality, other aspects can only be grasped in a differentiated way. Against the juxtaposition of a few church-traditional and many contemporary non-church pilgrims in Gamper and Reuter (2012), Heiser (2021) and Lienau $(2014,2018)$ emphasize the relevance of institutional religiosity for broad areas of pilgrimage. Pilgrimage- even if, as here, the focus is placed solely on pilgrimage on foot along the Way of St. James-is a phenomenon that is as complex as it is fluid and challenging to grasp.

As the phenomenon of pilgrimage is fluid and at the same time encompasses many motivational aspects it makes sense to use it as a paradigmatic indicator and trendsetter of a broader development. Pilgrimage can serve as a good example of the direction in which the religious field in Western Europe is currently moving. A traditional phenomenon is changing and taking on its own contemporary elements. The development of pilgrimage on foot on the Way of St. James was able to take hold quickly also because it had been largely dormant for decades (30 years ago, only 1/50 of the pilgrims registered today arrived in Santiago). This vacuum could be filled with new practices and therefore meanings.

Reflections on the religious-spiritual valence of pilgrimage can follow two perspectives. On the one hand, pilgrimage can be used as a mere metaphor without differentiated reference to practice. On the other hand, insights gained from the practice can be extrapolated exemplarily as indicators of late modern religiosity. On the one hand, the practice of pilgrimage is surveyed. On the other hand, pilgrimage is seen as a mere image of religious-cultural change (Schwaderer 2019).

As a metaphor, pilgrimage is encountered early on by Zygmunt Bauman (1994, “Vom Pilger zum Touristen"), and formatively by Danièle Hervieu-Léger (2004, "Pilger und Konvertiten. Religion in Bewegung") as an image of searching spirituality that does not commit itself. In Gebhardt et al. (2005), the "spiritual wanderer" becomes the ideal type of late modern religiosity. The outer movement of pilgrimage and its fluid shape become the image of the inner religious quest. Pilgrimage is not only a metaphor, but also an indicator of popular spirituality in Hubert Knoblauch (2009).

Lastly, a look at the media reveals some attractive features of pilgrimage to the mass. Media communication about pilgrimage is relatively independent of the practice, but it does provide indications of attractive aspects of pilgrimage that can be linked to it. An analysis of feature films popular in Germany shows that in many cases non-religious (sometimes even religion-rejecting) protagonists are religiously stimulated and affected from the outside by an imprinted ritualistic anachronistic-religious setting (Lienau 2015a). The contrast thus constructed between modern areligious pilgrims and anachronistic-religious settings precisely does not prevent the efficacy of the religious. Rather, it presents pilgrimage as attractive to modern people imagined as areligious. Through the framework, the pilgrim is given possibilities of behavior and interpretation that he no longer has of his own accord, but which can become significant for him despite all strangeness. 


\subsubsection{Results on Pilgrims' Religiosity and Spirituality: Motives and Self-Concept}

The general overview indicates that, beside all others, religious and spiritual (R/S) motives for pilgrimage coexist side-by-side. Acknowledging the multidimensionality of $\mathrm{R} / \mathrm{S}$ the question arises about its dimensions. This question has been addressed only indirectly in previous studies. Three areas have been dealt with in the analyses so far, but in many cases, they give only the following secondary indications:

1. the question of the denomination or religious affiliation of the pilgrims;

2. the question about the motives for pilgrimage;

3. the question about the experience on the road.

The subject of formal religious affiliation (1) says something only to a limited extent about the relevance and the content-related orientation of religiosity. Data on the motivation to go on pilgrimage (2) tells something about the situational interest in relation to the concrete intention to go on pilgrimage. Data on experiences on the road (3) also allow statements to be made about religiosity in the situation of pilgrimage, but not necessarily about the fundamental religious attitude and practice of the people on the way. Nevertheless, these aspects can be of heuristic use as secondary indications. At the same time, it must remain conscious that there is a clear deficit in knowledge about pilgrims here. In the following passage, some quantitative studies relevant to present research questions will be presented.

As a source on the relevance of religious and denominational affiliation and the religious self-concept for pilgrimage, the study by Farias et al. (2019) offers itself, which for the first time looks at decidedly atheistic pilgrims $(N=360$, including 290 members of a Christian church and 70 nondenominational). The two groups show no significant differences with respect to the following three of six motivation types: "closeness to nature", "search for live direction", and "spiritual seeking". In addition to many shared motives, there is an additional motive, "religious growth," among Christians, without this leading to relevantly weaker values for other motives. Overall, Farias et al. see pilgrimage as a flexible form for the religiously convinced, seekers and non-religious alike.

A comprehensive questionnaire studies $\left(N_{\text {total }}=1147\right)$ by Gamper and Reuter (2012) and Gamper (2014) show high values for a religious self-concept (43.9\% religious and $20.1 \%$ very religious), while only $7.6 \%$ described themselves as not religious. The values for selfdesignation as spiritual (32\%) and very spiritual (13.9\%) are comparably high with $17.1 \%$ rejecting any spiritual self-concept. Gamper and Reuter survey motivations and use them to form five types of pilgrims, with the non-religious-spiritually motivated pilgrims making up about half of the respondents. Among the individual items, "find yourself" (51.8\%), "escape from everyday life" (40.2\%), "enjoy silence" (39.2\%) and "feel spiritual atmosphere" $(34.6 \%)$ are at the top, as well as "nature"- i.e., motives that go in the direction of one's own self in the context of nature. These motifs form a kind of common denominator for many pilgrims, while explicitly religious motifs are still relevant for a subgroup.

Another comprehensive study that focuses on motivation comes from Amaro et al. (2018, $N=1140)$. Four of the eight assessed dimensions are strongly pronounced, i.e., "spirituality," "new experiences," "experience of nature," and "culture"; the other four motivations are significantly weaker, with values between two and three on a five-point scale: "religious motives," "keeping a vow," "getting to know places and people," and "breaking out of routines." In the case of respondents from religiously Catholic countries of origin (e.g., Portugal, Spain, Brazil), religious motives are more pronounced than in the case of pilgrims from more secularized and Protestant countries of origin.

Additionally, informative on the topic of motivation is a questionnaire study by Oviedo et al. (2014) with $N=470$. They are concerned with the question of whether pilgrimage is a "religious revival," a secular or post-secular form of nature tourism, or part of the trend of eclectic fuzzy spirituality. The result is that the latter type of spiritual pilgrim is predominant, but the different types can coexist well on the Camino de Santiago. Motives related to self ("spiritual growth," "sensations seeking," and "seeking life direction") are prioritized, with "religious growth" in the middle range, but certain traditional religious 
practices such as "penance" and "taking a vow" are rare. Self-designation as religious $(M=3.97$ on a scale of 1 to 10$)$ is noticeably lower than as spiritual $(M=5.90$ on a scale of 1 to 10). When asked about religious experiences on the road, only the item "Feeling the presence of God/the divine" achieved a slightly higher value with a mean of 3 on a 6-point scale. The two individual items with the highest values "to be close to nature" $(M=4.89)$ and "to find my deeper self" $(M=4.80)$ are interpreted by the authors as meaning that pilgrimage serves self-discovery, which is pursued through everyday distance and mystification of nature. Therefore, the authors conclude that the fact that the self-designation as spiritual has the strongest values speaks against the assumption of a strengthening of traditional religion and for a further development and a change in form of the religious towards the spiritual. In particular, the weak values for "religious devotion" show how much today's pilgrims differ from the pilgrim tradition. At the same time, traditional religiosity still plays a substantial role.

A study by Schnell and Pali (2013) emphasizes the moment of "quest", which $2 / 3$ of pilgrims cite as motivation, in opposition to "conviction". A two-dimensional scheme is elaborated on by the authors, as follows: dimension 1 represents the strength of vertical transcendence, dimension 2 the continuum from "quest" to "conviction." The dispersion on the transcendence scale showed average values compared to the normal population. At the same time, on dimension 2, the high values for self-knowledge, freedom, challenge, and self-realization show that the aspect of quest clearly distinguishes pilgrims from the normal population. The search for personal clarity is thus what most pilgrims have in common; the transcendence orientation is variable.

In an interview study, Heiser (2021) distinguishes between traditional religious and contemporary spiritual pilgrims. Although both types can be differentiated, there are fluid transitions and interferences at the same time. Millán Vázquez de la Millán Vázquez de la Torre et al. (2012) arrive at 91.4\% (exclusively or also) religious motives (and thus higher values than in the comparison group of a traditional pilgrimage in Andalusia). Gomes et al. (2019) construct a "touripilgrimage," that is, a pilgrimage that is more spiritual, ambiguous, and multi-motivational rather than solely religious. Because motives are increasing personally and spiritually, there is an increasing overlap between tourism, religion, and pilgrimage, they argue. Fernandes et al. (2012, $N=204)$ arrive at only $35 \%$ religious motives (with 39\% recreation, 33\% culture, 23\% curiosity, $17 \%$ sports, and $5 \%$ spirituality). Rather than tourist secularization or contrasting setting apart from one another, creative interactions of traditionally religious and non-traditionally religious pilgrims occur, they argue, and initially secular motives may shift toward spiritual ones along the way. In an analysis of online social network sources, Kim and Kim (2019) underscore the fluid self-attributions of pilgrims, most of whom are no longer clearly religious in the traditional sense, but neither are they secular or anti-religious, but rather oscillate between different religious stances. Pickard and Aitch (2020), using an online survey $(N=487)$ found significantly more pilgrims to have a spiritual $(81 \%$-only $3 \%$ reject it outright) than a religious $(45 \%)$ self-concept.

\subsubsection{Religiosity and Spirituality as a Topic of Pilgrimage Research}

In summary, the following can be said: the question of $R / S$ plays a substantial role in pilgrimage research despite the diversity and amalgamation of the motives in this field. The diversity leads to description of R/S via different concepts. Quite common in quantitative studies seems to be the approach via the motives of the pilgrims. However, in the narrower sense, this can only tell something about what the people intend with their pilgrimage. Only statements which are mediated and derived from this can be made about the religiousness of the pilgrims. In addition, there are-mainly qualitative-studies that examine expressions in relation to the carrying out of the pilgrimage, whether in interviews or in the analysis of digital media. In this way, something can be said about the religious valences of the pilgrimage practice (experiences, behavior, communication), but here too only derivatively does it speak of the pilgrims' religiosity. In addition to motives 
for pilgrimage and descriptions of the pilgrimage process, the question of denominational affiliation in quantitative studies forms a third access route. These data reflect the religiously diverse composition of the population and show that pilgrimage (on the Way of St. James) is no longer a purely Catholic phenomenon but also attractive to Protestant Christians and people without denominational affiliation (but hardly to people of other religions). However, it is questionable to what extent the mere denominational affiliation can provide information about the pilgrims' religiosity. For this, different aspects of religiosity would have to be surveyed, as the survey of the five dimensions in the centrality index of religiosity does. However, this has not yet been applied to pilgrims. This is the reason for the present study. Moreover, the subgroup of German-speaking pilgrims, which is important for a comparison with the normal population in Germany, Austria, and Switzerland, has almost never been studied specifically (Amaro et al. 2018).

\section{Method}

\subsection{Sample and Procedure}

The questionnaire for the study was developed in German and then translated into Spanish, English, and French. Thereby, it was understandable for a large part of the pilgrims on the Way of St. James. In the years 2017 and 2018, the questionnaires were displayed in different hostels or handed out in paper form by the hospitaleros upon arrival. Questionnaires were distributed exclusively in pilgrim-only hostels. This ensured that only pilgrims were surveyed. The completed questionnaires were largely handed-in directly on site, some were sent in by mail.

In total, 1142 filled in questionnaire forms were collected. However, the partial sample evaluated here includes only the 425 German-language questionnaires. Thereby, a comparison of the average population of German-speaking countries is possible and is intended. Table 1 shows how many questionnaires in German were completed at which location.

Table 1. Composition of the Sample of German-Speaking Pilgrims by Location.

\begin{tabular}{cccc}
\hline Country & Amount & Location & Amount \\
& & La Faba & 151 \\
Spain & & Pamplona & 55 \\
& Güemes & 49 & 9 \\
\hline Germany, Austria, Switzerland & & Astorga & \\
\hline Other country & 78 & & \\
\hline Not applicable & 6 & & \\
\hline Sum & 24 & & \\
\hline
\end{tabular}

Note. Only the questionnaires in German are listed.

As shown in Table 1, ca. 75\% of the German-language questionnaires were completed in pilgrim hostels in Spain. Another 19 percent can be assigned to places in Germany and Switzerland. The survey location hostel and the selection of locations have a sufficient distance to Santiago de Compostela, ensuring that the pilgrims, who completed the survey had mostly been on the way for a longer period. The survey sites in Spain are located on the main Camino Francés and the Camino del Norte, reflecting the different types of paths: the Spanish Main Way, the Secondary Way in the Iberian Peninsula, and the Camino de Santiago in the area of origin. Table 2 documents some demographic data of the Germanspeaking pilgrimage sample. In addition, it contains information on who the respondents are traveling with and whether they have previous experience with pilgrimages. 
Table 2. Demographics of the Sample of German-Speaking Pilgrims $(N=425)$.

\begin{tabular}{ccc}
\hline Category & Group & Percent \\
\hline Gender & female & 61.0 \\
\hline Age & up to 25 & 23.5 \\
& $26-40$ & 26.8 \\
& $41-60$ & 31.3 \\
& over 60 & 18.5 \\
\hline Education & without school degree & 1.4 \\
& secondary, vocational school & 26.9 \\
& baccalaureate & 25.0 \\
\hline Confession & college, university & 46.7 \\
\hline Traveling & none & 26.6 \\
& roman-catholic & 40.9 \\
& evangelical & 23.5 \\
\hline Pilgrimage Experience & alone & 46.9 \\
& pilgrimaged at least once before & 49.3
\end{tabular}

Note. Gender was assessed dichotomously.

\subsection{Instruments}

The four-page (A5-format) questionnaire consisted of 9 introductory questions about age, gender, education, health, and general information about the pilgrimage, 17 questions about the motivation for the pilgrimage, 22 questions on experiences during the pilgrimage, and 17 questions on R/S, which were asked at the end. Of the 17 questions on R/S, the answers to 9 questions are evaluated in the present study (see Table 3).

Table 3. Indicators for the Measurement of Religiosity and Spirituality.

\begin{tabular}{|c|c|c|}
\hline Facet & Indicator & Measure \\
\hline RSC & $\begin{array}{l}\text { All in all: How religious would you describe } \\
\text { yourself to be? }\end{array}$ & Single item \\
\hline SSC & $\begin{array}{l}\text { Regardless of whether or not you consider } \\
\text { yourself a religious person, how spiritual would } \\
\text { you describe yourself to be? }\end{array}$ & Single item \\
\hline Public practice & How often do you participate in church services? & Single item \\
\hline Ideology & $\begin{array}{l}\text { How strongly do you believe that there is God or } \\
\text { something divine? }\end{array}$ & \multirow{4}{*}{$\begin{array}{c}\text { Centrality of Personal } \\
\text { Religiosity Scale }\end{array}$} \\
\hline Intellect & How often do you think about religious issues? & \\
\hline Experience & $\begin{array}{l}\text { (a) interactive: How often do you experience } \\
\text { situations in which you have the feeling that } \\
\text { God or the divine is intervening in your life? } \\
\text { (b) participative: How often do you experience } \\
\text { situations in which you feel that you are one } \\
\text { with everything? }\end{array}$ & \\
\hline Private practice & $\begin{array}{l}\text { (a) interactive: How often do you pray? } \\
\text { (b) participative: How often do you meditate? }\end{array}$ & \\
\hline
\end{tabular}

Note. RSC-religious self-concept. SSC-spiritual self-concept. The dimensions of experience and private practice are operationalized by two indicators each ( $\mathrm{a}$ and $\mathrm{b}$ ), in which an interactive and a participative relation to transcendence is expressed. 
The theoretical foundation of the indicators used in the study is a multidimensional model developed to measure religiosity (Huber 2003; Huber and Huber 2012; Huber et al. 2020). The model presents a synthesis of the sociological approach to religion by Glock (1962; Stark and Glock 1968) and the psychological approach to religion by Allport (Allport and Ross 1967). The backbone of the model consists of five core dimensions (public practice, ideology, intellect, religious experience, and private practice), which are operationalized by indicators that are formulated as generally as possible. Moreover, to increase sensitivity to newer forms of religiosity and spirituality, private practice not only asks about prayer but also about meditation, and experience not only asks about the interactive experience by the intervention of a divine counterpart but also about the participatory experience of oneness with all. The scale used to measure the centrality of personal religiosity consists of one indicator each for the core dimensions ideology and intellect, and two indicators each for experience and private practice. However, only one value from these two core dimensions is included in the calculation of the scale value of the Centrality of Personal Religiosity Scale, namely the higher value in each case. The scale achieved an internal consistency of Cronbach's $\alpha=0.78$ among participants in the sample.

The model and the nine indicators are the theoretical and empirical core of the International Religion Monitor (Huber 2009; Huber and Krech 2009). In 2007, 2012, and 2017, representative surveys were conducted in a total of 23 countries as part of the Religion Monitor. In the 2017 survey wave, Germany, Austria and Switzerland were integrated, among others. For this reason, the responses of German-speaking pilgrims can be compared with population-representative data from the three countries. Moreover, meanwhile, a study has found evidence that the model for measuring religiosity has corroborated itself as a theoretical framework for coding qualitative interviews on spirituality (Demmrich and Huber 2019). Therefore, the five dimensions of this model can be used for the description and explanation of spirituality.

\subsection{Analyses}

In the first step, the analyses are based on descriptive statistics for each of the nine indicators from the multidimensional model of religiosity (see Table 3). Pairwise analyses lead to the fact that the $N$ differs slightly for the individual variables. Since findings from German-speaking pilgrims as well as from the representative comparison sample from Germany, Austria and Switzerland from the Religion Monitor 2017 are available for the same indicators, a comparison is also integrated into the description and interpretation of the results. To enable comparisons of German-speaking pilgrims with the normal German-speaking population in Germany, Austria and Switzerland, the representative data collected by the Religion Monitor 2017 in the three countries were pooled and then weighted according to the country shares of German-speaking pilgrims. Therefore, $t$-tests for independent samples are calculated on all available religious indicators. The results are reported with 95\% confidence intervals and Cohen's d effect size with Hedges' correction. Further, correlations between the indicators as well as the religious and spiritual selfconcept are analyzed using cross-tabulations and multiple regression analyses.

\section{Results}

The presentation of the results is delivered in the following steps: Firstly, there are the results of the centrality of personal religiosity scale. The distributions of the responses and mean values of the six indicators on the four core dimensions of religiosity that make up the scale for measuring the centrality of personal religiosity are presented (cf. Table 4). Thereafter, these are compared with representative results of the same indicators from the Religion Monitor 2017 in German-speaking countries (cf. Table 5). 
Table 4. Percentage distribution of responses and mean values of the six indicators on the four core dimensions of private practice, experience, intellect, and ideology among German-speaking pilgrims.

\begin{tabular}{|c|c|c|c|c|c|c|c|c|}
\hline & \multicolumn{3}{|c|}{ Private Practice } & \multicolumn{3}{|c|}{ Experience } & \multirow{2}{*}{ Intellect } & \multirow{2}{*}{ Ideology $b$} \\
\hline & Prayer & Meditation & $\mathrm{HV}^{\mathrm{a}}$ & Part. & Inter. & $\mathrm{HV}^{\mathrm{a}}$ & & \\
\hline$N$ & 407 & 408 & 414 & 395 & 397 & 409 & 411 & 392 \\
\hline never & 21.1 & 24.5 & 8.5 & 5.6 & 12.6 & 2.4 & 3.2 & 8.7 \\
\hline rarely & 29.2 & 28.4 & 25.6 & 21.5 & 18.6 & 11.7 & 20.4 & 11.7 \\
\hline occasionally & 17.2 & 27.0 & 25.8 & 39.5 & 31.5 & 36.2 & 31.4 & 15.3 \\
\hline often & 18.4 & 13.0 & 22.9 & 25.6 & 20.4 & 30.3 & 26.8 & 22.7 \\
\hline very often & 14.0 & 7.1 & 17.1 & 7.8 & 16.9 & 19.3 & 18.2 & 41.6 \\
\hline Mean ${ }^{c}$ & 2.75 & 2.50 & 3.15 & 3.09 & 3.10 & 3.52 & 3.37 & 3.77 \\
\hline
\end{tabular}

Notes. (a) "HV" (higher value) stands for the higher value of each of the two indicators on private practice and experience. If one of the two values is missing, the higher value counts as the missing value. For this reason, the $N$ of the HV variables is higher than the $N$ of the indicators from which they are calculated. (b) For religious ideology, the response scale does not consist of frequencies but of five intensity levels ("not at all", "not very much", "moderately", "quite a bit", "very much so"). (c) The mean should be interpreted in the given range of the scale of minimum 1.0 to maximum 5.0.

Table 5. Percentage distribution of responses and mean values of the six indicators on the four core dimensions of private practice, experience, intellect, and ideology in the normal population in Germany, Austria and Switzerland (weighted data).

\begin{tabular}{|c|c|c|c|c|c|c|c|c|}
\hline & \multicolumn{3}{|c|}{ Private Practice } & \multicolumn{3}{|c|}{ Experience } & \multirow{2}{*}{ Intellect } & \multirow{2}{*}{ Ideology ${ }^{b}$} \\
\hline & Prayer & Meditation & $\mathrm{HV}^{\mathrm{a}}$ & Part. & Inter. & $\mathrm{HV}^{\mathrm{a}}$ & & \\
\hline $\mathrm{N}$ & 2826 & 2847 & 2854 & 2751 & 2828 & 2863 & 2863 & 2826 \\
\hline never & 39.4 & 57.7 & 29.4 & 21.4 & 32.9 & 15.2 & 10.4 & 25.0 \\
\hline rarely & 26.2 & 20.5 & 27.2 & 33.2 & 26.1 & 26.1 & 24.5 & 18.1 \\
\hline occasionally & 10.6 & 9.5 & 14.3 & 27.7 & 24.3 & 31.5 & 33.9 & 16.4 \\
\hline often & 6.4 & 5.2 & 8.9 & 14.0 & 10.5 & 18.7 & 20.5 & 15.2 \\
\hline very often & 17.4 & 7.0 & 20.2 & 3.8 & 6.3 & 8.5 & 10.7 & 25.3 \\
\hline Mean population & 2.36 & 1.83 & 2.63 & 2.46 & 2.31 & 2.79 & 2.97 & 2.98 \\
\hline Mean pilgrims ${ }^{c}$ & 2.75 & 2.50 & 3.15 & 3.09 & 3.10 & 3.52 & 3.37 & 3.77 \\
\hline Mean difference & 0.39 & 0.67 & 0.52 & 0.63 & 0.79 & 0.73 & 0.40 & 0.79 \\
\hline
\end{tabular}

Notes. (a) "HV" (higher value) stands for the higher value of each of the two indicators private practice and experience. If one of the two values is missing, the higher value counts as the missing value. Therefore, the $N$ of the HV variables is higher than the $\mathrm{N}$ of the indicators from which they are calculated. (b) For religious ideology, the response scale consists of five intensity levels ("not at all", "not very much", "moderately", "quite a bit", "very much so") not of frequencies. (c) The penultimate row shows the mean values of the pilgrim sample from Table 3 for comparison. The last row "mean difference" shows the difference between the mean value of the pilgrims and the population (mean value pilgrims minus mean value population). All mean differences are significant $(p<0.001$ - detailed information on significant tests can be found in the Appendix A.

Secondly, the results of the analyses of the R/S self-concepts are presented. Later, the distribution of answers and mean values on the R/S self-concepts as well as the centrality of personal religiosity and the frequency of worship participation are described and compared in the pilgrimage sample (cf. Table 6) and the representative German-language samples from the Religion Monitor 2017 (cf. Table 7). 
Table 6. Percentage distribution of responses and mean values on religious and spiritual self-concept as well as the centrality of personal religiosity and the frequency of public religious practice among German-speaking pilgrims.

\begin{tabular}{|c|c|c|c|c|c|c|}
\hline & \multicolumn{2}{|c|}{ Religious Self-Concept } & \multicolumn{2}{|c|}{ Spiritual Self-Concept } & \multirow{2}{*}{$\begin{array}{c}\text { Centrality of } \\
\text { Personal Religiosity }\end{array}$} & \multirow{2}{*}{$\begin{array}{c}\begin{array}{c}\text { Public } \\
\text { Practice }\end{array} \\
406\end{array}$} \\
\hline$N$ & \multicolumn{2}{|c|}{385} & \multicolumn{2}{|c|}{395} & & \\
\hline not at all & 16.9 & 201 & 7.9 & 180 & 70 & 16.5 \\
\hline not very much & 22.3 & 39.1 & 13.2 & 18.0 & 7.9 & 34.5 \\
\hline moderately & \multicolumn{2}{|c|}{28.1} & \multicolumn{2}{|c|}{34.7} & 56.5 & 23.9 \\
\hline quite a bit & 19.0 & \multirow{2}{*}{32.8} & 35.6 & \multirow{2}{*}{47.4} & & 15.0 \\
\hline very much so & 13.8 & & 18.5 & & 35.6 & 10.1 \\
\hline Mean & \multicolumn{2}{|c|}{2.90} & \multicolumn{2}{|c|}{3.43} & 3.43 & 2.68 \\
\hline
\end{tabular}

Note. In the case of public practice, the response scale does not consist of intensities but of five frequency levels (never, rarely, occasionally, often, very often). For the Centrality of Personal Religiosity scale, the three sections are defined by the following scale values: low: 1.0-2.0, medium: 2.1-3.9, high: 4.0-5.0.

Table 7. Percentage distribution of responses and mean values on religious and spiritual self-concept and the centrality of personal religiosity and public religious practice in the normal population in Germany, Austria, and Switzerland (weighted data).

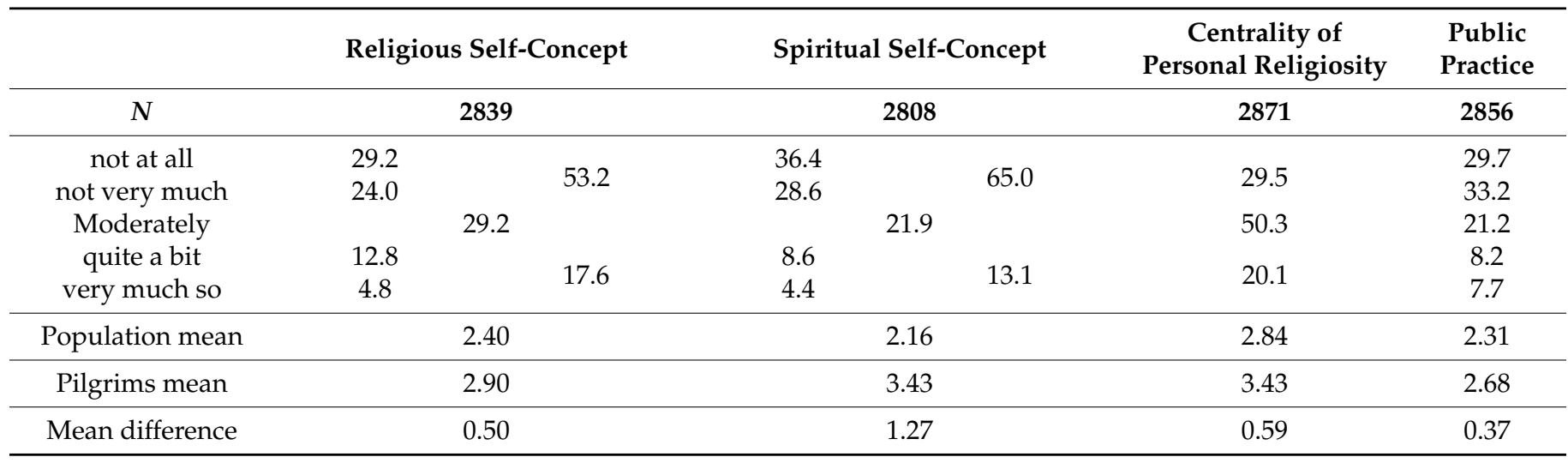

Note. Regarding worship attendance, the response scale does not consist of intensities but of five frequency levels ("never," "rarely," "occasionally," "often," "very often"). For the Centrality of Personal Religiosity scale, the three sections are defined by the following scale values: low: 1.0-2.0, medium: 2.1-3.9, high: 4.0-5.0.

The third step focuses on the in-depth analyses of the R/S self-concepts of the Germanspeaking pilgrims. For this, the distributions of the R/S self-concepts are first crosstabulated (cf. Table 8). Subsequently, step-by-step multiple regression analyses are reported to explain the religious and spiritual self-concept (cf. Table 9).

Table 8. Cross-tabulation of low, medium, and high expression of religious and spiritual self-concept among German-speaking pilgrims in percent $(N=376)$.

\begin{tabular}{|c|c|c|c|c|c|}
\hline & & Low & $\begin{array}{l}\text { Spiritual } \\
\text { Medium }\end{array}$ & High & Total \\
\hline \multirow{3}{*}{ religious } & low & $11.7 \%$ & $15.2 \%$ & $12.2 \%$ & $39.1 \%$ \\
\hline & medium & $3.7 \%$ & $13.3 \%$ & $11.2 \%$ & $28.2 \%$ \\
\hline & high & $2.4 \%$ & $6.6 \%$ & $23.7 \%$ & $32.7 \%$ \\
\hline \multicolumn{2}{|c|}{ total } & $17.8 \%$ & $35.1 \%$ & $47.1 \%$ & $100.0 \%$ \\
\hline
\end{tabular}

Note. The following response categories are combined in three categories: low ("not at all", "not very much"), medium ("moderately"), high ("quite a bit", "very much so"). 
Table 9. Stepwise Regression Analyses to Explain the Religious and Spiritual Self-Concept.

\begin{tabular}{|c|c|c|c|c|c|c|}
\hline & \multicolumn{3}{|l|}{ RelSelf } & \multicolumn{3}{|c|}{ SpirSelf } \\
\hline & $N$ & \multicolumn{2}{|c|}{341} & $N$ & \multicolumn{2}{|c|}{351} \\
\hline & $R^{2}$ & \multicolumn{2}{|c|}{0.68} & $R^{2}$ & \multicolumn{2}{|c|}{0.30} \\
\hline & IV & $\beta$ & $T$ & IV & $\beta$ & $T$ \\
\hline 1. & Prayer & 0.20 & 3.87 & Intellect & 0.22 & 3.89 \\
\hline 2. & Ideology & 0.25 & 5.29 & Meditation & 0.27 & 5.56 \\
\hline 3. & Public Practice (service) & 0.31 & 6.98 & Ideology & 0.30 & 4.84 \\
\hline 4. & Intellect & 0.18 & 4.54 & Experience (particip.) & 0.11 & 2.37 \\
\hline 5. & Experience (interact.) & 0.10 & 2.13 & Prayer & -0.13 & -2.08 \\
\hline
\end{tabular}

Note. RelSelf: religious self-concept. SpirSelf: spiritual self-concept. IV: independent variables. The order of the IV is based on the stepwise inclusion of the IV in the model.

\subsection{Descriptive Analyses of Personal Core Dimensions of Religiosity}

The four dimensions of private practice, experience, intellect, and ideology can be characterized as personal religiosity because they can be lived independently of membership in a religious community. Therefore, they are particularly meaningful for individualized religiosity and spirituality.

Notably, the results in Table 4 show that religious ideology is the most pronounced when comparing the five core dimensions among German-speaking pilgrims. Around $63 \%$ are fairly or very convinced that God or something divine exists. Thereafter, the intellectual dimension follows in second place, with $45 \%$ thinking about religious issues often or very often. Religious experiences are also highly pronounced. It is worth noting that the frequent presence ("often" or "very often") of interactive experiences is somewhat more widespread (about 37\%) than participatory experiences (33\%). Thus, if the higher frequency of both experiences is counted for each respondent, it can be stated that religious experiences are "often" or "very often" present in 50\% of pilgrims. On the other hand, only two percent of pilgrims report "never" having either form of religious experience. In terms of private practice, prayer is slightly more common than meditation, with $32 \%$ of pilgrims reporting that they pray "often" or "very often," compared to only $20 \%$ for meditation. At least one of the two private practices is followed "often" or "very often" by $40 \%$ of pilgrims. Therefore, regardless of the specific form, high frequency in private practice is remarkably common among pilgrims.

In the comparison with population data, it is immediately apparent that all dimensions of personal religiosity are significantly more pronounced among pilgrims. The difference is highest in religious ideology and the frequency of interactive religious experiences. In the normal population, only $40.5 \%$ "fairly" or "very" believe in God or the divine. In contrast, among pilgrims, the number is $64.3 \%$. Moreover, only $8.7 \%$ of pilgrims "do not believe at all," whereas this percentage is almost three times higher in the normal population at $25 \%$.

In the normal population, only $16.8 \%$ report that they "often" or "very often" experience situations in which they feel that God or something divine intervenes in their lives; among pilgrims, the amount is more than twice as high, at $37.3 \%$. In addition, only $12.6 \%$ of pilgrims say they "never" have interactive religious experiences, whereas this percentage is about two and a half times higher in the normal population, at $32.9 \%$.

Moreover, participative religious experiences are more pronounced among pilgrims than in the normal population. $33.4 \%$ of pilgrims say they "often" or "very often" experience situations in which they have the feeling of being one with everything. In the normal population, this number lies at $17.8 \%$. However, the difference of $15.6 \%$ points is smaller than for interactive religious experiences.

Finally, the difference between pilgrims and the normal population is weakest in the frequency of prayer and reflection. While only $23.8 \%$ pray "often" or "very often" in the normal population, this is the case for $32.4 \%$ among pilgrims. Moreover, when it comes to thinking about religious issues, the corresponding figures are $31.2 \%$ and $45 \%$. All reported differences are statistically significant on a $\alpha$-level of $5 \%$, two-sided. Please consider the 
information provided in the Appendix A Table A1 on the $t$-tests for more details on all difference calculations.

\subsection{Descriptive Analyses of Religious and Spiritual Self-Concept, Centrality of Personal Religiosity Scale, and Worship Attendance}

Table 6 shows the means and distributions of responses on items relating to R/S selfconcepts, frequency of worship attendance, and three areas of the scale on the centrality of personal religiosity (low: 1.0-2.0, medium: 2.1-3.9, high: 4.0-5.0). A low score on this scale indicates that a respondent rarely to never has religious experiences, does not engage in private religious practice, hardly thinks about religious issues, and does not believe in the existence of God or anything divine. Therefore, people in this group can be characterized as "non-religious." However, this is the case for only about eight percent of pilgrims. On the other hand, all four dimensions of personal religiosity are highly expressed in about $36 \%$ of pilgrims. Religiosity is often present in their life horizons in many ways. Therefore, they can be described as "highly religious" and religious content likely plays a central role in their lives. Around 57\% belong to the middle group. It is typical for them to have medium or fluctuating values for the four dimensions, both high and low. For this group, religiosity is important but not central. In other words, religion reappears again and again throughout the individual's lifespan but generally remains in the background.

The construct of the centrality of personal religiosity refers to private elements of the religious. To a certain extent, it expresses the "objective" occurrence and relevance of religious content in the horizon of life. However, the constructs of the R/S self-concepts are to be distinguished from this. They primarily refer to the level of religious consciousness and express how a respondent understands him/herself concerning the religious or spiritual. Nonetheless, there are correlations between these constructs; for example, the centrality of personal religiosity correlates very highly with the religious self-concept $(r=0.74)$ and highly with spiritual self-concept $(r=0.49)$. Nevertheless, it may be instructive to observe how religious-spiritual being and consciousness relate to each other in detail.

The values in Table 6 strongly indicate a preponderance of spiritual over religious consciousness. More than 80.0 percent of pilgrims consider themselves at least "moderately" spiritual, and almost half $(47.4 \%)$ consider themselves "fairly" or "very" spiritual. Being spiritual is thus a wide-spread self-image of pilgrims. In contrast, the situation is different for the religious self-concept. Only around one-third of pilgrims (32.8\%) describe themselves as "fairly" or "very" religious and another $28.1 \%$ as "moderately" religious. This contrasts with $39.1 \%$ of pilgrims who cannot identify with "religious" as a self-description. Thus, being religious is not a widely shared self-image of pilgrims, but rather a construct on which opinions differ. This issue is analyzed in more depth below in Table 7. Before doing so, it makes sense to compare the degree of personal religiosity of pilgrims as well as their R/S self-images with the corresponding values in the representative sample of the Religion Monitor 2017. The corresponding numbers can be found in Table 7.

Hence, a comparison of the values in Tables 6 and 7 shows that the mean value of the spiritual self-concept is higher the most-namely by 1.27 from 2.16 for the normal population to 3.43 for the pilgrims. In contrast, the mean values of the religious self-concept and the centrality of personal religiosity increase only by +0.50 and +0.59 , respectively. The mean difference is reflected in the response categories. While $65 \%$ of the normal population describe themselves as "not at all" or "not very" spiritual, only $18 \%$ of pilgrims do so. On the other hand, the opposite is true for the self-description as "quite" or "very" spiritual. In the normal population, only about $18 \%$ describe themselves as "quite" or "very" spiritual; among pilgrims, this figure rises to $47.4 \%$. That is more than two and a half times higher. Finally, the difference is smallest in the frequency of public practice. More information on the significance tests of pilgrim's and population's values can be found in the Appendix A Table A1. 


\subsection{Cross-Analyses of the Spiritual and Religious Self-Concept}

How does spiritual relate to religious self-understanding? The bivariate Pearson's correlation coefficient between the two variables is $r=0.40(N=376 ; p<0.001)$. This coefficient has a medium magnitude, indicating that the two constructs mostly go hand-inhand. At the same time, it is low enough that substantial variation is possible in addition to the general tendency. Therefore, it makes sense to analyze the relationship of the answers to both constructs in more detail in a cross-tabulation. For this purpose, Table 8 compares three levels of the two self-concepts: low ("not at all", "not very much"), medium ("moderately"), high ("quite a bit", "very much so").

Primarily, it can be seen that the two concepts "spiritual" and "religious" are equally pronounced in $48.7 \%$ of the pilgrims- $11.7 \%$ : low, $13.3 \%$ : medium, $23.7 \%$ high. See the diagonal in Table 8. A gradual shift is found in another $36.7 \%-26.4 \%$ emphasize the spiritual self-concept somewhat more strongly $(15.2 \%+11.2 \%)$, and $10.3 \%$ give gradual priority to the religious self-concept $(3.7 \%+6.6 \%)$. In contrast, a mutually exclusive understanding of $\mathrm{R} / \mathrm{S}$ is present in $14.6 \%$ of pilgrims. Only $2.4 \%$ of pilgrims see themselves as "highly religious" and at the same time as "low" spiritual. After all, $12.2 \%$ of pilgrims exclusively describe themselves as "highly spiritual" and reject the term "religious" as a category relevant to identity. In summary, the following results can be drawn regarding the use of the terms "religious" and "spiritual" among the pilgrims surveyed:

1 Most pilgrims in the sample see themselves as spiritual (35.1\% as "medium spiritual" and $47.1 \%$ as "highly spiritual").

2 For most pilgrims, the concepts of "spiritual" and "religious" are not mutually exclusive. For $37 \%$ of pilgrims, both categories are equally pronounced in a medium or high degree. Another $26.4 \%$ report a gradual dominance of the spiritual self-concept. A gradual dominance of the religious self-concept is present in $10.3 \%$.

3 A minority of around 15\% of pilgrims use the concepts of "spiritual" and "religious" as mutually exclusive categories. The largest part of this group (about 12\%) exclusively sees itself as highly spiritual.

Finally, the question of how the R/S self-concepts are related to the core dimensions of religiosity is addressed. To clarify this question, stepwise regressions were calculated on both variables. Therein, the religious self-concept (RelSelf) and spiritual self-concept (SpirSelf) are defined as dependent variables (DV). The other seven indicators from Table 1 are defined as independent variables (IV) and are integrated into the regression analyses stepwise according to their explanatory potential. Table 9 documents the most important statistical parameters of the final solutions. For the correlations of the variables in the regression equations please see Table $\mathrm{A} 2$ in the Appendix A.

$\beta \beta$ Regarding the two multiple regression analyses documented in Table 9, the following aspects can be highlighted: globally, the regression analysis on religious self-concepts explains $68 \%$ of the variance in the dependent variable. The strength of the religious selfconcept can thus largely be explained based on the expressions of the five core dimensions of centrality of religiosity. The explanatory potential of the frequency of public practice is highest among all $(\beta=0.31)$. This indicates that attachment to a religious institution plays an essential role in the self-attribution of religious identity. However, in addition, all four core personal dimensions make substantial contributions in explaining the religious self-concept. This means that seeing oneself as religious is not only related to a religious social body but also substantially related to lived personal religiosity. In the dimensions of private practice and religious experience, only the interactive forms of prayer and the experience of God's intervention are significant predictors.

Around 30 percent of the variance of the spiritual self-concept is based on the expression of the core dimensions of centrality of religiosity. Compared with the religious self-concept, this is less than half. This shows that other factors besides lived religiosity play a significant role in the pilgrims' spiritual self-concept. The highest explanatory potential is that of religious ideology $(\beta=0.30)$. This indicates that the belief in the existence of a spiritual level of reality plays a significant role in the self-attribution of a spiritual 
identity. Further, it can be highlighted that public practice does not play a significant role in explaining the spiritual self-concept. In the dimensions of private practice and experience, only the participatory forms of meditation and unity experience are significant predictors with a positive association. Moreover, regarding the interactive practice of prayer, there is a negative correlation. That is, as the frequency of prayer increases, the likelihood of a high expression of spiritual self-concept decreases. In conclusion, these findings suggest that the strength of the spiritual self-concept more strongly corresponds with other forms of religious practice than it is the case with the religious self-concept.

\subsection{Summary of the Results}

The following main results can be highlighted from the analyses:

- German-speaking pilgrims in the present sample have substantially higher values on all dimensions of religiosity than the general population in Germany, Austria, and Switzerland. The differences are highest in the dimensions of religious ideology and the experience of the intervention of divine authority. Pilgrims believe more strongly in the existence of a spiritual reality and experience interaction with this reality more often.

- More than $80 \%$ of pilgrims of the sample consider themselves to be moderately (35\%) or highly $(47 \%)$ spiritual. In this respect, the difference to the population in Germany, Austria and Switzerland is by far the greatest.

- For most pilgrims, the categories religious and spiritual are not mutually exclusive. However, there is a qualified minority of around $12 \%$ who define themselves as spiritual in an exclusive way.

- Compared to the religious self-concept, the expression of the spiritual self-concept is less dependent on lived religiosity and is partly shaped by other forms of religiosity.

\section{Discussion}

\subsection{Sample of German-Speaking Pilgrims}

The German-speaking pilgrims in the present study are mostly female (61\%), mainly have high school diplomas or higher $(72 \%)$, about half are making their first pilgrimage $(54 \%)$, most are traveling alone (47\%) or in a small group (49\%), and most are members of the Catholic Church (41\%)-cf. Table 2. Restraining from comparisons one thing to point out is that this demographic pattern is similar in terms of most parameters to the data from the two comprehensive studies by Amaro et al. (2018) and Gamper and Reuter (2012), in which the proportions of women are $57 \%$ and $44 \%$, respectively, $83 \%$ and $80 \%$ have high school diplomas or higher, respectively, and $52 \%$ and $70 \%$ are first-time pilgrims, respectively. The proportion of members of the Catholic Church is higher in Gamper and Reuter (2012), at $66 \%$. This might be explained by the fact that most of their sample is composed of three Catholic countries (Spain, Italy, France). All the studies use convenience samples to analyze their questions. Therefore, conclusions in the presented examination are limited to German-speaking walking and cycling pilgrims on the Way of St. James. However, this is a valuable piece of information for the study of the pilgrimage on the Way of St. James.

\subsection{Dimensions of the Pilgrims' Religiosity}

An important question in pilgrimage research is to what extent today's pilgrims are religious. The data of the present study provide an approach to that question with empirical evidence about German-speaking pilgrims on the Way of St. James in the light of the multidimensional model of religiosity. They show considerably higher values in all dimensions of religiosity compared to the normal German-speaking residents of Switzerland, Austria, and Germany. Religiosity is most elevated in the dimensions of experience, ideology, and private practice of meditation. This illustrates that pilgrimage on the Way of St. James is particularly characterized by a strongly heightened awareness of the existence of a spiritual level of reality and that this belief is also expressed in religious experiences and practices. Pilgrimage on the Iberian Peninsula today is thus also essentially 
characterized by a lived religiosity. In contrast, the type of a purely secular pilgrim is minoritarian in the present sample. Only 9\% do not believe at all in the existence of a spiritual reality and even only around $2 \%$ state that they have no religious experiences at all.

These results are relevant for walking and cycling pilgrimage research, insofar as comparisons with representative data from the normal population have rarely been made in the literature. An exception is the results of Oviedo et al. (2014), which are based on data from the year 2010. With respect to the Spanish pilgrims in their sample $(N=134)$, when comparing them to Spanish data from the 2010 European Social Survey (ESS), they found that there was little difference in the frequency of prayer and worship attendance between pilgrims and the normal population ("ibid., p. 436"). Based on this, they concluded that the Way of Saint James "does not draw a specific type of person from the general population-the most religious, for example-but rather a representative subset of the general population" (ibid.). Regarding the German-speaking pilgrims who traveled the Way of St. James in 2017 and 2018, such a conclusion cannot be made. On the contrary, the religiosity and spirituality of pilgrims is higher compared to the normal population. Pilgrims to the Camino de Santiago are sensitive in religious and spiritual terms. The extent to which the strong difference in the results of the two studies can be attributed to different pilgrimage cultures in Spain and in German-speaking countries or to temporal changes in pilgrimage culture in general must be clarified by further studies.

The strong values for faith and the existence of God in absolute terms and in comparison with the normal population questions the assumption that pilgrims on the Way of St. James trend toward a fluid, vague and indeterminate religiosity (according to Oviedo et al. 2014). It seems that not vagueness, but a concise certainty of God is typical for at least the pilgrims it the present sample, not a specific style that is clearly distinguishable from the normal population, but an overall significantly stronger religiosity on all indicators of the centrality of religiosity.

\subsection{Spiritual and Religious Self-Concepts}

The results of the present study bring evidence that the lived religiosity of Germanspeaking pilgrims on the Way of St. James in the sample is significantly higher than that of the normal German-speaking population. Their awareness of their own religiosity and spirituality is more pronounced. The difference is particularly high in the spiritual selfconcept. Around $47 \%$ of the sample describe themselves as fairly or very spiritual, which is almost four times the proportion in the normal population. In contrast, only around $33 \%$ of the respondents describe themselves as fairly or very religious, which tends toward doubling the proportion in the normal population.

The finding that pilgrims identify more strongly with the concept of spirituality than with the concept of religiosity is well documented in pilgrimage research. Pickard and Aitch (2020) report that 39\% of pilgrims in their study describe themselves as "very spiritual" and $11 \%$ as "very religious" on a four-point scale. Oviedo et al. (2014) found that for pilgrims, the goal of "spiritual growth" is much more important than "religious growth." Amaro et al. (2018) report that for pilgrims, "spiritual motivations" are significantly higher than "religious motivations." In this regard, the results from present study are in line with the previous research. This leads to the next point of discussion.

\subsection{Spirituality as 'Commonsense'}

In the present study, over $80 \%$ describe themselves as moderately and highly spiritual. Highly religious and at the same time low spiritual participants are hardly found. Among them, it seems that almost universally shared spiritual self-concept forms a commonsense. A religious and a spiritual self-image are not mutually exclusive. Pointedly, religiosity saddles itself to spirituality, extends and complements it. In the present study, of pilgrimage, there is spirituality without religiosity, but hardly any religiosity without spirituality. 
Thus, the results differ from those of other studies that work (based on motives) with a juxtaposition of religion and spirituality (including Oviedo et al. 2014; Farias et al. 2019; Gamper and Reuter 2012). A contrasting juxtaposition, which is often linked to attributes such as traditional and contemporary, seems therefore to be too simplistic here. In the selfimage of the participants, this either exists or it does not exist. Among them, spirituality is a common denominator. For many pilgrims, religiosity is added to spirituality. A subgroup is exclusively spiritual.

\subsection{Pilgrimage as a Religious, Spiritual or Secular Phenomenon?}

Many studies question whether the religious aspects of pilgrimage are dissipating, blending, becoming diluted, or relating only to subgroups of pilgrims. Often, a shift from a purely religious to a touristical-spiritual phenomenon is claimed (Kim et al. 2019; LoisGonzález and Santos 2015; Lopez et al. 2017). Moscarelli et al. (2020) state, "Currently, it is acultural, touristic, monumental, spiritual, and sports route ... As a result, its original 'space of faith' is now a 'liveheritage space'". Gomes et al. (2019) construct under the term "touripilgrimage" an ambiguous amalgamation in which tourist and religious-spiritual motifs are mixed. Others emphasize the diversity of motives and structure them into different types of pilgrims (Gamper and Reuter 2012; Oviedo et al. 2014). What stays?

Based on the results of the present study, some claims from the past can be questioned, as follows: the above-average religiosity of participants of the present study would be an argument against a tourist leveling without wiping it out. Other aspects (such as sports, nature, or sociability) may well also play a role. This said, based on the underlying observations, religiosity remains an essential aspect of pilgrimage.

From the perspective of the present study, how does the formation of different pilgrim types-according to which religion is relevant for a subgroup of pilgrims but not for pilgrims as a whole-unfold (Gamper and Reuter 2012)? In view of only $2.4 \%$ pilgrims with a low religious and spiritual self-concept, the construction of secular-only pilgrim types can be doubted. Relative to the normal population, but also in absolute terms, the number of exclusively non-religious pilgrims is very small.

\subsection{Interactive-Participative Patterns}

Spirituality can be defined in terms of various aspects. One distinction is that made by Huber between interactive and participatory (Huber et al. 2020), which finds evidence support in a broad worldwide application in the Religion Monitor (Huber 2009). It can be described in terms of types of religious experience-'God's intervention' versus 'being one with all'. It can be linked to an analogous distinction of private practice-prayer versus meditation. Additionally, it can be associated with a transcendent versus immanent understanding of God. Pilgrims and pilgrimage (Lienau 2015b, and some argue ultimately contemporary spirituality in general) are sometimes claimed to have a strong prevalence of participatory experience and practice, and worldview, respectively. Is pilgrimage an indicator or a trendsetter for this? The present study suggests being cautious with this kind of assertion. The absolute values of the pilgrims in the sample show a certain dominance of interactive spirituality in terms of practice and experience. This remains true in comparison to the normal population. The relatively stronger increases in participatory practice and experience are presumably due to the strong bodily and natural experiential possibilities of pilgrimage. Participatory patterns are also prevalent among pilgrims. It is rarely the case that one pattern excludes the other. Here, the same observation as with R/S self-concepts seems to fit into the picture. It is more a kind of interplay than counterplay.

\subsection{Conflict or Interaction of Traditional and Contemporary Religiosity/Spirituality?}

In the discussion of contemporary pilgrimage, the juxtaposition of two topoi is often encountered-traditional religion and contemporary spirituality. Besides models of detachment or demarcation, there are also models of creative and enriching interaction of 
traditional and contemporary religiosity (Heiser 2021; Fernandes et al. 2012), with pilgrims oscillating between both poles.

This observation can in some respects be deepened and clarified by the present study; whereas Kim et al. (2019) describe pilgrims' shifting self-attributions as change and fluidity, the present study suggests explaining this fact rather as a conjunction of spirituality and religiosity, vertical and horizontal self-transcendence in the pilgrims' self-concept. Virtually all pilgrims in the present study have a spiritual self-concept. Many, but by no means all, participants supplement this with a religious self-concept. This is not at the expense of the spiritual self-concept, but in many cases augments it. The results provide evidence for the picture of a fusion rather than switching or interaction between two different types drawn in other studies. Rather, it is a matter of a shared basis in spirituality that a large subgroup supplements with religiosity, which can also be shaped by denominational affiliation and public practice, e.g., Sunday service or alike.

Future studies may focus more on behavior and experiences on the Way and relate these to pilgrims' self-concepts, motives, and centrality of religiosity. Why do certain rituals, such as the pilgrim's blessing in Roncesvalles, the stone-laying at the Cruz de Ferro and participation in the pilgrim's mass in Santiago, have very broad participation, while this is often not the case for participation in evening masses, for example? How (intensively) do exchanges occur between pilgrims of different religions? Are there conflicts among pilgrims related to their different religiosity? For example, do differently religious pilgrims have different experiences and behave differently? Another point of research can refer to the change of religiosity and spirituality on the way. One can hypothesize that the R/S is changing all the way down to the destination point and a study designed to collect data systematically along the way could inform evidence to this question.

\section{Conclusions}

Pilgrimage's rising attraction over the last decades offers the possibility to have a deeper insight in the underlying structure of its motives, as well as religiosity, and spirituality of the pilgrims. The present study takes the step to look at the phenomenon closer through the lens of the multidimensional model of centrality of religiosity. Coming back to the principal questions of the examination after the discussion, some brief inferences can be made.

1. Generally, said multidimensional model worked out for pilgrims' religiosity and spirituality with no detectable flaws. Questionnaires worked well to assess the phenomenon on the journey of pilgrims on the Way of St. James.

a. Pilgrims in the sample do believe in the existence of a spiritual realm.

b. Most pilgrims in the sample think about transcendence at least rarely, only $3.2 \%$ never think of religious issues.

c. Pilgrims in the sample seek contact with the transcendency by prayer or meditation to different degrees. Only about $9 \%$ never do private religious practice. In terms of experience regarding transcendency it is the case for about $98 \%$, only $2 \%$ never have such religious experiences.

d. About 3/4 of the sample are affiliated with a Christian church. Most of them identify themselves with the Catholic church.

2. Pilgrims in the sample could provide information on both the religious and the spiritual self-concept.

a. "Religious" seems to be to a lesser extent a point of reference to the participants of the study (about 60\%), whereas

b. "Spiritual" provides a point of reference to more participants (about $80 \%$ )

3. The religious and spiritual self-concept of pilgrims can partly be explained by the dimensions of the multidimensional model or religiosity. The religious one more than the spiritual one, $68 \%$ and $30 \%$, respectively, of explained variances, respectively. 
4. The pilgrims in the present sample differ from the population in Germany, Austria, and Switzerland regarding the dimensions of the multidimensional model of religiosity by showing higher mean values on every core dimension. Regarding the religious and spiritual self-concepts same conclusion can be drawn. The aspects of higher ideological and experiential values are especially pronounced for pilgrims.

The results show the facets of the $\mathrm{R} / \mathrm{S}$ on a convenient sample of German-speaking pilgrims on the Way of St. James. Clearly, there are limits to generalization of the results. The sample in the present study is not collected systematically enough to represent most of the pilgrims. Research in the field is always a trade-off. However, with several hundred participants of walking and cycling pilgrims on the way of St. James from different location on the path it provides a view on the phenomenon for the German-speaking of them. Additionally, the collected data has some ecological validity, insofar as some practical derivations can still be made. The next two paragraphs focus on implications for tourism professional and church institutions as well as for researchers.

\subsection{Stakeholders: Tourism Professionals and Churches}

What are the tasks for tourism and religious actors in the field? The discussion of pilgrimage in tourism science shows that the tourism potential of pilgrimage has been recognized. Two partial results of the present study are predominantly relevant for tourism: pilgrims on the Way of St. James are more religious than average. How can their specific needs, in contrast to the rest of tourism, be met? Additionally, there is a spiritual core, on which a religious matter is built upon. Besides a small subgroup that sees itself as exclusively spiritual, there is a larger group that combines religion and spirituality in the self-concept. Tourist operators can assume that they can reach virtually all walking and cycling pilgrims on the Iberian Peninsula with a spiritual approach, but they should not ignore the relevant group with a pronounced religiousness.

In pilgrims, church actors on pilgrimage routes have an attractive target group of people with above-average religious-spiritual resonances. At the same time, many of the pilgrims are not church members-both nominally as non-members and by the form of their religiosity. Pronounced interactive religiosity stands next to pronounced participatory religiosity, highly religious next to less religious pilgrims. A differentiated understanding of the target group of walking and cycling pilgrims and their internal structure helps in the development of adequate offers.

It is essential for the church institutions to understand that a trend toward spiritual patterns does not have to be at the expense of (church) religiosity. Rather, a "superimposition" of religious self-concept on spiritual one can be observed. For the church, it is not advisable to wean itself off spirituality, because it can build its religiosity well on it.

The fact that many pilgrims with pronounced religiosity do not describe themselves as religious should make the churches sit up and take notice. The current perception of religion leads people to distance themselves from it rather than identify with it. If this reticence is due to a distancing from outdated ecclesiastical pilgrimage practices such as vows, relic, and indulgence piety, then it is advisable for churches to offer other accessible and attractive practices that tap into the religious potential that pilgrims bring with them.

\subsection{Outlook: Research Perspectives}

A principal question for walking, cycling and other forms of pilgrimage research is whether the strong orientation toward motives is sustainable. Apparently, self-designations allow valid statements about pilgrims' motives only to a limited extent. Therefore, the present study - which has only evaluated a part of the data collected on the Way of St. James, namely the one in German language-surveys the following different levels: demographic data, accomplishment of pilgrimage, motives for pilgrimage, experiences during pilgrimage and R/S of pilgrims. This informs the examination from different points of view and allow a broader look on the phenomenon. A multidimensional view on the phenomenon seems 
to find corroboration in the evidence of the present examination. This aligns with the common understanding of $\mathrm{R} / \mathrm{S}$ as multidimensional.

By concentrating on the R/S of pilgrims in the analysis, correlations between the facets should come into view, e.g., how does religiosity shape motivation for pilgrimage? Do people expect pilgrimage to renew their religiosity and spirituality or rather reinforce their existing attitudes?

The following is another question for future research, one which might be related to the actual experiences made during pilgrimage: (how) does religiosity shape experiences along the way? Does an interactive or participatory religiosity match a corresponding experience on the road, or are the two rather independent? Additionally, the association with the type of pilgrimage as a factor (stage length, type of co-pilgrims) could help to deepen the insight between religiosity and pilgrimage practice.

The presented examination referred solely to the German-language subsample. A comparative evaluation of the other sub-samples with the languages English, French and Spanish can tie in more closely with the international discussion and enable an international comparison.

Author Contributions: Conceptualization, D.L. and S.H.; Data curation, M.A. and S.H.; Formal analysis, M.A. and S.H.; Investigation, D.L., Methodology, S.H. and M.A.; Project administration, D.L.; Software, S.H. and M.A.; Supervision, D.L. and S.H.; Validation, D.L., S.H. and M.A.; Writingoriginal draft, D.L., S.H., and M.A.; Writing—review and editing, M.A. All authors have read and agreed to the published version of the manuscript.

Funding: This research received no external funding.

Data Availability Statement: The data that support the findings of this study are available from the corresponding author upon reasonable request.

Conflicts of Interest: The authors declare no conflict of interest.

Statistical Disclaimer: Any rounding errors are due to the software used in this investigation. The authors report any numbers with the best given method available at the time of manuscript writing.

\section{Appendix A}

Table A1. $t$-tests of the mean differences between the pilgrim sample and the weighted sample of German speakers from Germany, Austria, and Switzerland.

\begin{tabular}{cl}
\hline Core dimension & Test Results for the Difference of Sample and Population Data \\
\hline \multirow{2}{*}{ Ideology } & $\Delta$ Mean $=0.79,95 \% C I[0.67 ; 0.92], t(545.49)=13.39, p<0.001$, \\
& Cohen's $d=0.52,95 \% C I[0.42 ; 0.63]$ \\
Intellect & $\Delta$ Mean $=0.40,95 \% C I[0.28 ; 0.51], t(3271.89)=6.65, p<0.001$, \\
& Cohen's $d=0.35,95 \% C I[0.25 ; 0.45]$ \\
& $\Delta$ Mean $=0.63,95 \% C I[0.52 ; 0.74], t(536.56)=11.55, p<0.001$, \\
Interactive Experience & Cohen's $=0.58,95 \% C I[0.48 ; 0.69]$ \\
Participatory Experience & $\Delta$ Mean $=0.79,95 \% C I[0.67 ; 0.92], t(3222.66)=12.20, p<0.001$, \\
& Cohen's $d=0.65,95 \% C I[0.55 ; 0.76]$ \\
Prayer & $\Delta$ Mean $=0.39,95 \% C I[0.25 ; 0.53], t(556.20)=5.36, p<0.001$, \\
& Cohen's $d=0.27,95 \% C I[0.16 ; 0.37]$ \\
Meditation & $\Delta$ Mean $=0.66,95 \% C I[0.54 ; 0.79], t(3252.71)=10.30, p<0.001$, \\
& Cohen's $d=0.54,95 \% C I[0.44 ; 0.65]$ \\
Public Practice & $\Delta$ Mean $=0.36,95 \% C I[0.23 ; 0.48], t(3269.26)=5.59, p<0.001$, \\
& Cohen's $d=0.30,95 \% C I[0.19 ; 0.40]$ \\
Religious Self-concept & $\Delta$ Mean $=0.50,95 \% C I[0.38 ; 0.63], t(3222.33)=7.86, p<0.001$, \\
& Cohen's $d=0.43,95 \% C I[0.32 ; 0.53]$ \\
Spiritual Self-concept & $\Delta$ Mean $=1.27,95 \% C I[1.15 ; 1.39], t(3201.05)=20.88, p<0.001$, \\
& Cohen's $d=1.12,95 \% C I[1.01 ; 1.23]$ \\
\hline
\end{tabular}


Table A2. Correlations of the nine indicators of religiosity and spirituality.

\begin{tabular}{|c|c|c|c|c|c|c|c|c|}
\hline & Ideology & Intellect & $\begin{array}{l}\text { Interactive } \\
\text { Experience }\end{array}$ & $\begin{array}{l}\text { Participatory } \\
\text { Experience }\end{array}$ & Prayer & Meditation & $\begin{array}{l}\text { Public } \\
\text { Practice }\end{array}$ & $\begin{array}{c}\text { Religious } \\
\text { Self-Concept }\end{array}$ \\
\hline Intellect & 0.53 & & & & & & & \\
\hline Interactive Experience & 0.69 & 0.52 & & & & & & \\
\hline Participatory Experience & 0.17 & 0.26 & 0.41 & & & & & \\
\hline Prayer & 0.66 & 0.51 & 0.60 & 0.27 & & & & \\
\hline Meditation & 0.23 & 0.29 & 0.28 & 0.28 & 0.35 & & & \\
\hline Public Practice & 0.49 & 0.45 & 0.38 & 0.15 & 0.70 & 0.21 & & \\
\hline Religious Self-concept & 0.69 & 0.60 & 0.60 & 0.20 & 0.73 & 0.22 & 0.69 & \\
\hline Spiritual Self-concept & 0.42 & 0.42 & 0.40 & 0.26 & 0.31 & 0.39 & 0.26 & 0.39 \\
\hline
\end{tabular}

Note. All correlations listed are significant at the $\alpha<0.05$ level, two-sided.

\section{Note}

1 When speaking of pilgrimage in the following, it refers exclusively to contemporary pilgrimage on foot (or by bike), which has spread from the Camino Francés to Camino de Santiago and other pilgrimage routes in Europe-and still prototypically and frequently takes place on the great Camino de Santiago to Santiago de Compostela. Knowing that there are many other forms of pilgrimage, here, for the sake of ease of reading, the term pilgrimage is used in the text.

\section{References}

Allport, Gordon W., and J. Michael Ross. 1967. Personal religious orientation and prejudice. Journal of Personality and Social Psychology 5: 432-43. [CrossRef] [PubMed]

Amaro, Suzanne, Angela Antunes, and Carla Henriques. 2018. A closer look at Santiago de Compostela's pilgrims through the lens of motivations. Tourism Management 64: 271-80. [CrossRef]

Bauman, Zygmunt. 1994. Vom Pilger zum Touristen. Das Argument 205: 389-408. Available online: http://www.neu.inkrit.de/ mediadaten/archivargument/DA205/DA205.pdf (accessed on 20 November 2021).

Collins-Kreiner, Noga. 2016. Researching pilgrimage: Continuity and Transformations. Annals of Tourism Research 37: 440-56. [CrossRef]

Demmrich, Sarah, and Stefan Huber. 2019. Multidimensionality of Spirituality: A Qualitative Study among Secular Individuals. Religions 10: 613. [CrossRef]

Emilio Estevez, director. 2010, The Way. London and Barcelona: Icon Entertainment Int., Filmax Entertainment and Elixir Films.

Farias, Miguel, Thomas J. Coleman III, James E. Bartlett, Lluís Pedro Pestan, Pedro Pestana Soares, Tiago Santos, and María del Carmen Bas. 2019. Atheists on the Santiago Way: Examining Motivations to Go on Pilgrimage. Sociology of Religion 80: 28-44. [CrossRef]

Fernandes, Carlos, Elsa Pimenta, Francisco Gonçalves, and Susana Rachão. 2012. A new research approach for religious tourism: The case study of the Portuguese route to Santiago. International Journal of Tourism Policy 4: 83-94. [CrossRef]

Gamper, Markus. 2014. Die HRW 2012 und Pilgern nach Compostela: Ausdruck zeitgenössischer Spiritualität und Religion?-Ein Empirischer Vergleich. Available online: https://jakobsweg.ch/assets/Uploads/14-04-26-Pilgern-und-Wallfahren-Gamper.pdf (accessed on 20 November 2021).

Gamper, Markus, and Julia Reuter. 2012. Pilgern als spirituelle Selbstfindung oder religiöse Pflicht? Empirische Befunde zur Pilgerpraxis auf dem Jakobsweg. In Doing Modernity—Doing Religion. Edited by Daniel Anna, Franka Schäfer, Frank Hillebrandt and Hanns Wienold. Wiesbaden: Springer VS, pp. 205-31.

Gebhardt, Winfried, Martin Engelbrecht, and Christoph Bochinger. 2005. Die Selbstermächtigung des religiösen Subjekts. Der »spirituelle Wanderer « als Idealtypus spätmoderner Religiosität. Zeitschrift für Religionswissenschaft 3: 133-52. [CrossRef]

Glock, Charles Y. 1962. On the study of religious commitment. Religious Education 57: 98-110. [CrossRef]

Gomes, Carlos, Nieves Losada, and Xerardo Pereiro. 2019. Motivations of pilgrims on the Portuguese Inner Way to Santiago de Compostela. International Journal of Religious Tourism and Pilgrimage 7: 5. [CrossRef]

Heiser, Patrick. 2021. Pilgrimage and Religion: Pilgrim Religiosity on the Ways of St. James. Religions 12: 167. [CrossRef]

Herbers, Klaus. 2006. Jakobsweg. Geschichte und Kultur einer Pilgerfahrt. München: Beck.

Hervieu-Léger, Danièle. 2004. Pilger und Konvertiten. Religion in Bewegung. Würzburg: Ergon.

Huber, Stefan. 2003. Zentralität und Inhalt. Ein neues multidimensionales Messinstrument der Religiosität. Opladen: Leske \& Budrich.

Huber, Stefan. 2009. Religion Monitor 2008: Structuring Principles, Operational Constructs, Interpretive Strategies. In What the World Believes: Analysis and Commentary on the Religion Monitor 2008. Edited by Bertelsmann Stiftung. Gütersloh: Verlag Bertelsmann Stiftung, pp. 17-51.

Huber, Stefan, and Odilo W. Huber. 2012. The Centrality of Religiosity Scale (CRS). Religions 3: 710-24. [CrossRef]

Huber, Stefan, and Volkhard Krech. 2009. The Religious Field between Globalization and Regionalization-Comparative Perspectives. In What the World Believes: Analysis and Commentary on the Religion Monitor 2008. Edited by Bertelsmann Stiftung. Gütersloh: Verlag Bertelsmann Stiftung, pp. 53-93.

Huber, Stefan, Michael Ackert, and Herbert Scheiblich. 2020. Religiosität in unterschiedlichen Religionskulturen - Vergleiche auf der Basis der Centrality of Religiosity Scale. Cultura E Psyché 1: 171-85. [CrossRef] 
Kerkeling, HaPe. 2006. Ich bin dann mal weg. Meine Reise auf dem Jakobsweg. München: Piper.

Kim, Bona, and Seongseop (Sam) Kim. 2019. The Effect of Religious Tourism Experiences on Personal Values. International Journal of Religious Tourism and Pilgrimage 7: 9. Available online: https://arrow.dit.ie/ijrtp/vol7/iss2/9 (accessed on 20 November 2021). [CrossRef]

Kim, Hany, Semih Yilmaz, and Soyoun Ahn. 2019. Motivational Landscape and Evolving Identity of a Route-Based Religious Tourism Space: A Case of Camino de Santiago. Sustainability 11: 3547. [CrossRef]

Knoblauch, Hubert. 2009. Populäre Religion. Auf dem Weg in eine spirituelle Gesellschaft. Frankfurt/M: Campus.

Lienau, Detlef. 2014. Ist Pilgern individualisierte Religion? Über Subjektivität, Sozialität und Autonomie religiöser Wanderer. In Individualismus_-Genealogien der Selbst(er)findung. Edited by Cédric Duchêne-Lacroix, Felix Heidenreich and Angela Oster. Berlin: Lit Verlag, pp. 123-37.

Lienau, Detlef. 2015a. Am Ende des Weges werden alle Sünden erlassen. Pilgern im Spielfilm. Praktische Theologie 50: 115-22. [CrossRef]

Lienau, Detlef. 2015b. Religion auf Reisen. Eine Empirische Studie zur Religiösen Erfahrung von Pilgern. Freiburg im Breisgau: Kreuz Verlag.

Lienau, Detlef. 2018. Individualisierung von Religion? Pilgern zwischen religiöser Subjektivität und Autonomieverlust. Zeitschrift für Religionswissenschaft 26: 85-107. [CrossRef]

Lois-González, Rubén C., and Xosé M. Santos. 2015. Tourists and pilgrims on their way to Santiago. Motives, Caminos and final destinations. Journal of Tourism and Cultural Change 13: 149-64.

Lopez, Lucrezia, Rubén C. Lois González, and Belén María Castro Fernandez. 2017. Spiritual Tourism on the way of Saint James and the current situation. Tourism Management Perspectives 24: 225-34. [CrossRef]

Margry, Peter Jan. 2015. To Be or not to Be ... a Pilgrim. Spiritual Pluralism Along the Camino Finisterre and the Urge for the End. In Heritage, Pilgrimage and the Camino to Finisterre. GeoJournal Library. Edited by Cristina Sánchez-Carretero. Heidelberg: Springer, vol. 117, pp. 175-211. [CrossRef]

Millán Vázquez de la Torre, Maria G., Leonor M. Pérez Naranjo, and Roberto C. Carranza. 2012. Analysis of the Pilgrim Profile in Spain: Two Case Studies. International Journal of Applied Science and Technology 2: 23-29.

Moscarelli, Rossella, opez, ucrezia, and Rubén C Lois González. 2020. Who Is Interested in Developing the Way of Saint James? The Pilgrimage from Faith to Tourism. Religions 11: 24. [CrossRef]

Nilsson, Mats, and Mekonnen Tesfahuney. 2016. Performing the "post-secular" in Santiago de Compostela. Annals of Tourism Research 57: 18-30. [CrossRef]

Oficina del Peregrino Homepage. n.d. Estadísticas Antiguas. Available online: https://oficinadelperegrino.com/estadisticas/ (accessed on 20 November 2021).

Oviedo, Lluis, Scarlett de Courcier, and Miguel Farias. 2014. Rise of Pilgrims on the Camino to Santiago: Sign of Change or Religious Revival? Review of Religious Research 56: 433-42. [CrossRef]

Pickard, Joseph G., and Gina T. Aitch. 2020. Pilgrimage, Spirituality, and Personal Transformation. Available online: https:/ /www.umsl. edu/socialwork/files/pdfs/CVs/pilgrimage,-spirituality,-and-personal-transformation-pickard.pdf (accessed on 20 November 2021).

Schnell, Tatjana, and Sara Pali. 2013. Pilgrimage today: The meaning-making potential of ritual. Mental Health, Religion $\mathcal{E}$ Culture 16: 887-902. [CrossRef]

Schwaderer, Isabella. 2019. Pilgern—eine religionswissenschaftliche Einordnung eines zeitgenössischen Phänomens. Theologie der Gegenwart 62: 95-106.

Stark, Rodney, and Charles Y. Glock. 1968. American Piety: The Nature of Religious Commitment. Berkeley: University of California Press. 